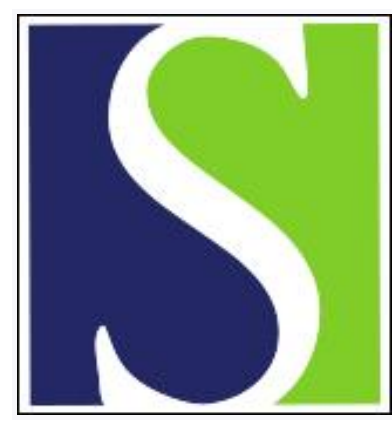

Scand J Work Environ Health 1998;24(5):367-375

https://doi.org/10.5271/sjweh.357

Issue date: Oct 1998

The accident process preceding overexertion back injuries in nursing personnel

by Engkvist I-L, Hagberg M, Wigaeus Hjelm E, Menckel E, Ekenvall L, PROSA study group

The following articles refer to this text: 2002;28(6):394-401;

2003;29(6):468-477; 2014;40(1):74-81

Key terms: back; cluster analysis; lifting; nurse; patient transfer

This article in PubMed: www.ncbi.nlm.nih.gov/pubmed/9869308 


\title{
The accident process preceding overexertion back injuries in nursing personnel
}

\author{
by Inga-Lill Engkvist, BSc, ${ }^{1,2}$ Mats Hagberg, MD, ${ }^{1,4}$ Ewa Wigaeus Hielm, PhD, ${ }^{1}$ Ewa Menckel, PhD, ${ }^{1}$ Lena \\ Ekenvall, MD, ${ }^{3}$ PROSA study group
}

\begin{abstract}
Engkvist I-L, Hagberg M, Wigaeus Hjelm E, Menckel E, Ekenvall L, PROSA study group. The accident process preceding overexertion back injuries in nursing personnel. Scand J Work Environ Health 1998;24(5):367-375.
\end{abstract}

\begin{abstract}
Objectives This prospective dynamic-population-based study investigated factors involved in the accident process preceding overexertion back injuries among nursing personnel.

Methods The study covered all reported occupational overexertion back injuries due to accidents among of the approximately 24500 nurses in the Stockholm County hospitals during 1 year. It was assumed that several factors interact in the accident process. Detailed information was obtained for each injury by interviews with the injured nurse and head nurse. Risks in the physical environment were identified using an ergonomic checklist.

Results During the study 136 overexertion back injuries were reported. Of the 130 nurses participating in the study, 125 had been injured in connection with patient work. Cluster analysis yielded 6 clusters and their pattern of contributing factors. The most frequent injury occurred during patient transfer in the bed or to or from the bed, without the use of transfer devices, when the patient suddenly lost his or her balance or resisted during the transfer and the nurse had to make a sudden movement. However, there were physical conditions, such as shortcomings in the physical work environment or a lack of a transfer device, that compelled the nurses to perform the tasks under unsafe conditions.

Conclusions The clusters showed a complexity of different kinds of accidents and indicated that the measures for preventing accidents, or for blocking an accident process once started, have to be of different kinds and placed at several different levels in the organization of a workplace.
\end{abstract}

Key terms back, cluster analysis, lifting, nurse, patient transfer.

Nurses have a documented high risk of work-related back injuries (1-4). Nursing aides in Sweden have a relative risk of 6.0 for reported occupational accidents leading to an overexertion back injury when compared with all other employed Swedish women (5). Most injuries occur during patient transfer and lead to a long sick leave, an average of 59 days, the indication being that they cause both personal suffering and a high social cost. According to Troup, most published reports dealing with the causes of back injuries consider a single causative factor and thus ignore other contributory factors (6). Before preventive measures can be suggested, it is important to investigate carefully the circumstances involved in the accident process. Studies using interview methods to obtain qualitative data may identify factors contributing to the onset of occupational back pain (7).
The purpose of this study was to investigate factors involved in the accident process preceding overexertion back injuries among nursing personnel.

\section{Subjects and methods}

\section{Definitions}

The use and definitions of the concepts accident and injury vary from researcher to researcher (8-11). In the present study the following definitions were used: injury is the pathogenic outcome of physical harm; the accident process, with which this study is concerned, consists of the 2 preinjury phases, an initial and a concluding phase, described in the Occupational Accident Research Unit

National Institute for Working Life, Solna, Sweden.

Section of Rehabilitation Medicine, Department of Surgical Sciences, Karolinska Institute, Stockholm, Sweden. Department of Occupational Medicine, Karolinska Hospital, Stockholm, Sweden.

Department of Occupational Medicine, Sahlgrenska University Hospital, Göteburg, Sweden.

Reprint requests to: Ms Inga-Lill Engkvist, National Institute for Working Life, 171 84 Solna, Sweden. [E-mail: ingalill@ niwl.se] 
(OARU) model $(12,13)$. In the initial phase, there are deviations from the planned or normal process (eg, shortage of staff or a transfer device out of order). The concluding phase is characterized by loss of control and the ungoverned flow of energy (eg, a nurse acts suddenly to prevent a patient from falling). In the 3 rd phase of the OARU model, the injury phase, energies meet the human body and cause physical harm (eg, as in the present study, overexertion of any of the tissues in the back). Patient transfer in this study refers to all forms of transfer in which the nurse supports the patient to some extent.

\section{Study assumption model}

The study assumption was that several factors interact in the accident process and lead to a back injury. In the model below (figure 1), these factors are illustrated under 4 headings: organization, workplace, nurse, and patient. Organization refers to, for example, the kind of task performed, lack of information to the nurse, the co-worker, or shortage of staff. Workplace includes the place and deficiencies in the physical environment, such as lack of space, which compel the nurse to work in an awkward position. There can also be a lack of transfer devices. The nurse may have chosen a nonoptimal way of performing the task despite her knowledge and the opportunity to perform the task in a more laborsaving way or she has been compelled to work in an awkward position. The patient may have been uncooperative during the transfer due to a physical or psychological handicap, suddenly lost his or her balance or resisted, or could have been seriously overweight.

\section{Study base}

The study population consisted of all general registered nurses, state registered nurses, and auxiliary nurses, approximately 24500 persons in all, who were employed in the Stockholm County hospitals during a period of 12 months (March 1992 - February 1993). General registered nurses have the longest education of the 3 occupational groups, with medical responsibility and supervisory function including administrative tasks. The state

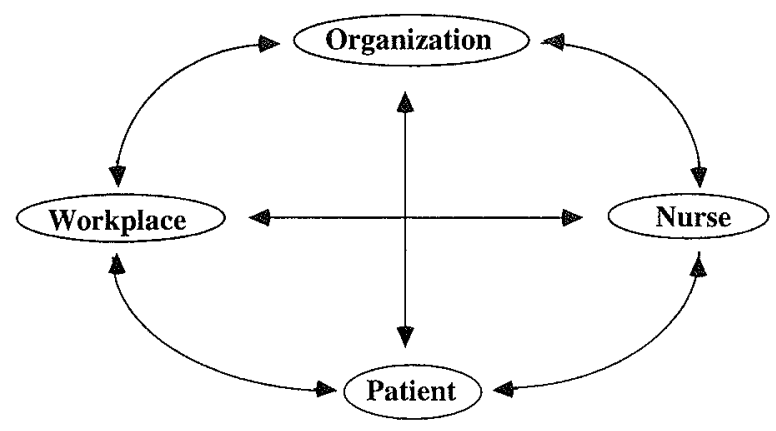

Figure 1. Model for factors interacting in an accident process leading to an overexertion back injury among nurses. registered nurses and the auxiliary nurses have rather similar tasks with practical care of patients, but the auxiliary nurses have less professional education. Throughout the rest of this report, all 3 occupational groups will be called nurses. The inclusion criterion was that the nurse had reported, on a work injury insurance form, a workrelated overexertion back injury that could be referred to a certain time and place and therefore coded as an occupational accident. The nurse should also have worked for at least 1 week during the 3 months preceding the injury. The reported injury was included in the study irrespective of its severity, what back tissues had been injured, or whether it led to sick leave. For ethical reasons it was decided to exclude nurses working in psychiatric hospital care since, in such work, patient violence constitutes a more severe problem than overexertion back injuries.

\section{Study design}

The study was designed as a prospective, dynamic-population-based investigation. In Sweden, all working persons are compulsorily insured for occupational injuries. Such injuries should be reported on an injury form. The form is sent by the employer to the social insurance office with a copy to the occupational health care unit. In the present study, when this copy arrived, an investigator from an occupational health care unit contacted the injured person and made an appointment for an interview. The time spans between the accident and the injury report and between the accident and the interview were registered.

\section{Interviews}

Standardized protocols for systematic structured interviews, based on the assumption model, were used. One protocol was used for the nurse who had reported the overexertion back injury and another was used for the head nurse of the injured person's ward. In addition an ergonomic checklist was followed (14). The interview protocol for the injured person started with an unstructured description of the accident process, which was recorded entirely. To get as many details as possible, the interviewers helped the nurses by asking questions like: "Why?" "What happened before that?" and "What was it about the equipment, patient, surroundings, organization of the work, yourself, or those around you that could have brought about the accident?" The free description was followed by 84 questions, based on the model, the factors related to organization, the workplace, the nurse, and the patient. The interview with the head nurse included 38 questions focused on organizational matters. Both interviews ended with comments from the interviewers, who could note their impressions of how well the person remembered the details concerning the accident process. The interviewers were 12 ergonomists, 
employed in occupational health care and specially trained in interview techniques. The interviews were carried out at the workplaces, in privacy. In a few cases the nurse was interviewed by telephone.

\section{Data processing}

Based on the information from the interview with the injured nurse, a conditional probability model (15) with the categories patient work, patient transfer, planned transfer, use of transfer devices, and type of patient transfer was calculated.

To identify the main types of accident process and the pattern of contributing factors concerning patient work (125 cases), 22 factors regarded as likely to be involved in the accident processes were studied. These factors were based mainly on the free description given by the injured person, but also on answers to some of the specific questions in the protocol, the interview with the head nurse (staffing, patient's weight), and the ergonomic checklist (found risks in the physical environment which contributed to the investigated accident). Furthermore, if relevant, the type of patient transfer was included. Three experts in ergonomics (I-LE, MH, EWH) independently assessed whether each of the 22 factors was not simply present but also if it directly contributed to the accident process by reviewing the free description, the 2 interview protocols, and the checklist. The 22 assessed factors fell into the following 5 categories: (i) organization: if there was lack of staff, there was a lack of information to the nurse with respect to transfer technique or how to use the transfer devices, there was a lack of information concerning the patient's current condition that day, there was a requirement for rehabilitation by the patient's physician, the nurse felt rushed or stressed, the nurse transferred the patient alone, the co-worker lacked training in transfer techniques or lost hold of the patient; (ii) workplace: if there was a risk in the environment, there were no proper transfer devices or they were out of order, the nurse was compelled to work in an awkward position when performing the task because of some external factor (eg, lack of space); (iii) nurse: if the nurse herself chose an awkward position for performing the task, there was a misunderstanding or lack of communication between the nurse and patient, the nurse was compelled to make a sudden movement (eg, to save the patient from falling); (iv) patient: if the patient weighed $80 \mathrm{~kg}$ or more, the patient suddenly lost balance or resisted; and (v) type of patient transfer: in bed, to or from bed, to or from the toilet, walking, from the floor, to or from a trolley or $\mathrm{X}$ ray table, other transfer.

The expert's assessments were compared, and, in a few cases of disagreement on whether a certain factor contributed to the accident or not, there was a discussion until full agreement was achieved. To identify groups of accidents that were relatively homogeneous with respect to the 22 dichotomous factors, a cluster analysis was performed. The analyses were based on the Dice similarity measure for dichotomous data, which puts stronger weight on the joint presence of a factor than on the joint absence between 2 cases. The clusters were formed using the average linkage-within-groups method, which minimizes the average distance between all pairs in a cluster (16). Different numbers of clusters (5-8) were tested. The chi-square was calculated for all the factors for an indicator of how significantly a factor discriminated between clusters. All the analyses were performed with the SPSS program (17). Two outliers representing unique accident processes were excluded from the analysis. One occurred when the nurse, as she stated, sat in an unusual position feeding a patient and in the other the nurse was adapting an artificial leg to a patient.

\section{Results}

\section{Reported injuries}

During the study period, 136 nurses reported an overexertion back injury due to an accident. Six nurses declined to participate in the study. Hence, 130 reported accidents remained in the study, 119 affected women and 11 men. The time span between the accident and the injury report averaged 12 (range $0-127$ ) days, and between the accident and the interview the average length of time was 114 (range 22-464) days. None of the nurses reported more than 1 accident during the study. The injured persons had a mean age of 32 (range $18-61$ ) years. Two percent of the injured nurses had been working less than 1 month in the profession, while $60 \%$ had been working 6 years or longer. With respect to the specific task being performed, $78 \%$ of the nurses had had 3 or more years' experience when the accident occurred (table 1).

Nearly $60 \%$ of the occupational injuries were reported by state registered nurses, and about $20 \%$ by

Table 1. Approximate proportion of the study population, mean age, and experience with the specific task being performed when the reported injury occurred, by occupation $(N=130)$.

\begin{tabular}{|c|c|c|c|c|c|c|c|}
\hline \multirow[t]{2}{*}{ Occupation } & \multirow{2}{*}{$\begin{array}{l}\text { Proportion } \\
\text { of study } \\
\text { population } \\
(\%)\end{array}$} & \multirow{2}{*}{$\begin{array}{c}\text { Proportion } \\
\text { of } \\
\text { injured } \\
(\%)\end{array}$} & \multicolumn{2}{|c|}{$\begin{array}{c}\text { Age } \\
\text { (years) }\end{array}$} & \multicolumn{3}{|c|}{$\begin{array}{l}\text { Experience with } \\
\text { specific task (\%) }\end{array}$} \\
\hline & & & Mean & Range & $\begin{array}{l}>1 \text { week- } \\
<1 \text { year }\end{array}$ & $\begin{array}{l}1-2 \\
\text { years }\end{array}$ & $\geq 3$ years \\
\hline $\begin{array}{l}\text { Registered } \\
\text { general } \\
\text { nurse ( } N=26 \text { ) }\end{array}$ & 53 & 20 & 36 & $21-54$ & 4 & 17 & 79 \\
\hline $\begin{array}{l}\text { State } \\
\text { registered } \\
\text { nurse }\{N=77\}\end{array}$ & 30 & 59 & 32 & $19-59$ & 8 & 24 & 68 \\
\hline $\begin{array}{l}\text { Auxiliary } \\
\text { nurse ( } \mathrm{N}=27 \text { ) }\end{array}$ & 17 & 21 & 33 & $19-61$ & 4 & 4 & 92 \\
\hline
\end{tabular}

a Proportion of study population based on statistics for number of nurses employed in Stockholm County (Personal communication S-M Lindqvist, Federation of Swedish County Councils). 
registered general nurses and auxiliary nurses (table 1). In $44 \%$ of the cases the nurse had a sick leave (median 14 days, range 1 day -8 months), and medical care was sought by half (55\%). Analgesics were taken by $64 \%$. Altogether $39 \%$ of the nurses had experienced a similar overexertion back injury earlier. Of these, half $(52 \%)$ had reported their injury on a work injury insurance form.

\section{Organization}

Nearly all the injuries occurred while the nurse was working with a patient, most often during patient transfer (figure 2). The most frequent form of patient transfer involved movement in the bed or to or from the bed. Other activities were, for example, washing or feeding the patient. In 5 cases the injury occurred while objects were being moved. The weights of the objects were either more than $31 \mathrm{~kg}$ (eg, bed or trolley without patient) or less than $5 \mathrm{~kg}$ (eg, X-ray cassette).

In half of the events (52\%) 2 nurses cooperated, in $13 \%$ there were 3 or more nurses handling the transfer, and in $35 \%$ the nurse performed the task alone. Of the last mentioned, $52 \%$ of the nurses said that they usually managed alone, and $18 \%$ said there was no one else

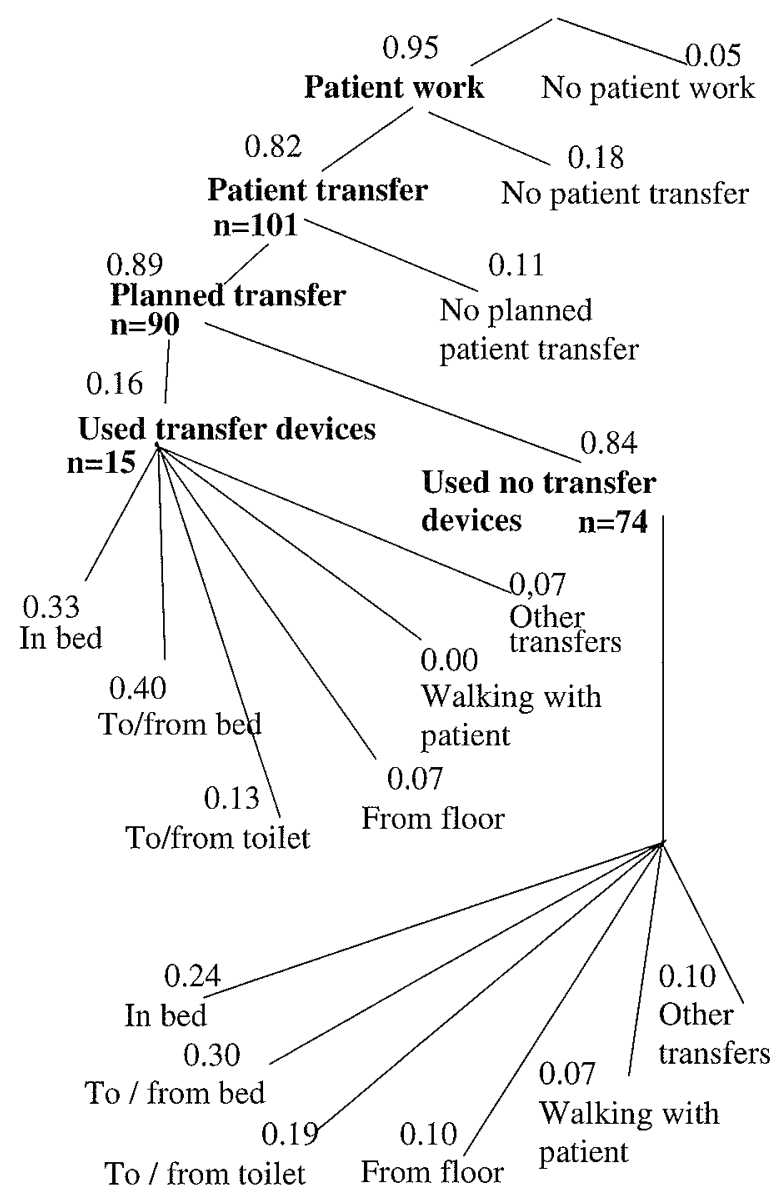

Figure 2. Probability tree for the different tasks performed $(N=130)$. available. When several nurses took part in the patient transfer, most often all were experienced with the procedure or the assisting device ( $87 \%$ ), but in $13 \%$ of the cases 1 nurse was inexperienced.

Most of the accident processes involved a planned activity (figure 2); in other words, the nurse had time to consider how to perform the task and whether a device should be used, for example, during an ordinary patient transfer from a bed to a chair. In $11 \%$ of the accidents, the nurse had to take sudden action, for example, when a patient was falling out of the bed and the nurse tried to prevent the fall. As seen in figure 2, transfer devices were used in $16 \%$ of the patient transfers. The reasons most often given by the nurse for not using a transfer device were that she did not think it was necessary, there was not enough space, there was no suitable transfer device, the devices were inconveniently stored, and there was an emergency. The devices most often used were a walking belt or a draw sheet.

The specific task, as during the concluding phase, was usually performed one to several times a day by $46 \%$ of the nurses and several times per hour by $10 \%$. The task was performed in the way the nurse was used to doing it in $71 \%$ of the accidents. In $8 \%$ it was the first time the nurse had performed the task. Sixty-five percent of the nurses said they had enough time to plan how to perform the task.

\section{Workplace}

The site for the concluding phase was the patient's room in $59 \%$ of the cases, a toilet in $12 \%$, and a corridor in $11 \%$. The remaining reported sites were treatment rooms, $\mathrm{X}$-ray rooms, showers, emergency entrances, and the like. Most injuries occurred in surgical wards (23\%), medical wards $(17 \%)$, or wards for the chronically ill $(13 \%)$. The rest were spread over the remaining wards.

\section{Nurse}

Eighty percent of the nurses said they had followed given instructions when performing the task. The reasons given by the injured person for not following instructions were, for example, that it would have taken too long, there was not enough space, it was an emergency, it was inconvenient, and so forth.

\section{Patient}

The patients weighed between 33 and $180 \mathrm{~kg}$, average $81 \mathrm{~kg}$. The patient's possibility to co-operate during the transfer was limited. In $47 \%$ of the cases the limitation was physical, in $6 \%$ psychological, in $37 \%$ both. In $9 \%$ of the accidents there were other limitations, for example, the patient was unconscious or anesthetized. All told, one-third of the events occurred with wheelchair patients, when they were being transferred between the bed and the wheelchair (20\%) or between the toilet and the wheelchair $(13 \%)$. 


\section{Number of patient transfers}

In the assessment of contributing factors included in the cluster analysis, the ergonomic experts and the injured persons assessed the patient transfer differently. In the interviews, transfers of a bed, trolley, or wheelchair with a patient in it had not been reported as patient transfers. Neither had all transfers in bed, such as turning the patient. Therefore, the numbers of patient transfers in the conditional probability tree, which was based on the interviews with the nurses, differed from the number in the cluster analysis, where the experts' assessments were used.

\section{Clusters}

When 6 clusters were performed, they showed 6 welldefined types of accident processes. Table 2 presents the extent to which the 22 different factors contributed to each cluster.

Cluster 1: transfer to or from bed or toilet. Most of the reported injuries in cluster 1 , the largest (43 cases) occurred during patient transfers to and from or to or from the bed or toilet (table 2). The accident process often started with the patient's loss of control, or resistance, during the transfer. Thus the nurse had to make a sudden movement to prevent the patient from falling. In half of the cases, the nurse was compelled to work in awkward positions due to a risk in the physical environment, most often lack of space or a shortage of staff. Misunderstandings or lack of communication between the nurse and the patient contributed to about half of the accident processes. There was a lack of information concerning the patients' condition in one-third of the cases. A lack of in formation on transfer techniques or the patient's heavy weight contributed to nearly the same extent. To some degree all the factors tested contributed to the accident processes in this cluster. The cluster was solid; not until 8 clusters were performed was it divided, depending on whether it was a transfer to or from the bed or to or from the toilet.

Cluster 2: nurse compelled to work in awkward position. In cluster 2 (39 cases) most of the nurses were compelled to work in an awkward position due to a lack of a trans fer device or a risk in the physical environment, most often a lack of space. The most frequent patient transfers took place in bed. In one-fifth of the cases "other

Table 2. Clusters (number of accidents in parehtheses) and the proportion of the factors assessed as directly contributing to the accident process in each cluster. The 5 most common factors in each cluster (except cluster 5) are in boldface. The P-value for the chi-square is an indicator of how well the clusters are differentiated by the factor. (cluster $1=$ transfer to or from bed or toilet, cluster 2 $=$ nurse compelled to work in an awkward position, cluster $3=$ nurse walked alone with patient, cluster $4=$ unaided transfer of a patient in bed or to or from bed, cluster $5=c 0$-worker lost grip on patient during transfer in bed, cluster $6=$ nurse chose awkward position due to stress)

\begin{tabular}{|c|c|c|c|c|c|c|c|}
\hline Factors & $\begin{array}{l}\text { Cluster } 1 \\
\qquad(\mathrm{~N}=43)\end{array}$ & $\begin{array}{c}\text { Cluster } 2 \\
(N=39)\end{array}$ & $\begin{array}{c}\text { Cluster } 3 \\
(N=13)\end{array}$ & $\begin{array}{c}\text { Cluster } 4 \\
(N=14)\end{array}$ & $\begin{array}{r}\text { Cluster } 5 \\
(N=4)\end{array}$ & $\begin{array}{c}\text { Cluster } 6 \\
(N=10)\end{array}$ & P-value \\
\hline \multicolumn{8}{|l|}{ Organization } \\
\hline \multicolumn{8}{|l|}{ Lack } \\
\hline Staff & 0.28 & 0.21 & 0.00 & 0.07 & 0.00 & 0.10 & 0.138 \\
\hline Information on transfer techniques & 0.28 & 0.31 & 0.15 & 0.29 & 0.25 & 0.00 & 0.425 \\
\hline Information on patient's condition & 0.33 & 0.00 & 0.08 & 0.00 & 0.00 & 0.00 & 0.000 \\
\hline Rehabilitation demands & 0.12 & 0.00 & 0.39 & 0.00 & 0.00 & 0.00 & 0.000 \\
\hline Stress & 0.14 & 0.54 & 0.08 & 0.50 & 0.00 & 0.90 & 0.000 \\
\hline Transferred alone & 0.30 & 0.28 & 0.69 & 1.00 & 0.00 & 0.20 & 0.000 \\
\hline Co-worker & 0.12 & 0.08 & 0.00 & 0.00 & 1.00 & 0.00 & 0.000 \\
\hline \multicolumn{8}{|l|}{ Workplace } \\
\hline Risk in physical environment & 0.47 & 0.60 & 0.23 & 0.21 & 0.00 & 0.00 & 0.002 \\
\hline Lack of transfer device & 0.14 & 0.62 & 0.23 & 0.14 & 0.00 & 0.30 & 0.000 \\
\hline Compelled to work in awkward position & 0.51 & 0.85 & 0.15 & 0.43 & 0.00 & 0.00 & 0.000 \\
\hline \multicolumn{8}{|l|}{ Nurse } \\
\hline Chose an awkward position & 0.16 & 0.03 & 0.08 & 0.57 & 0.50 & 1.00 & 0.000 \\
\hline Misunderstanding or lack of communication & 0.51 & 0.26 & 0.31 & 0.07 & 0.00 & 0.00 & 0.002 \\
\hline Compelled to make a sudden movement & 0.74 & 0.36 & 0.85 & 0.07 & 0.50 & 0.10 & 0.000 \\
\hline \multicolumn{8}{|l|}{ Patient } \\
\hline Patient weight $>80 \mathrm{~kg}$ & 0.28 & 0.56 & 0.15 & 0.57 & 0.00 & 0.20 & 0.006 \\
\hline Patient lost control & 0.88 & 0.49 & 0.92 & 0.07 & 0.25 & 0.30 & 0.000 \\
\hline \multicolumn{8}{|l|}{ Patient transfer } \\
\hline In bed & 0.02 & 0.31 & 0.16 & 0.43 & 1.00 & 0.00 & 0.000 \\
\hline To or from bed & 0.54 & 0.15 & 0.00 & 0.36 & 0.00 & 0.20 & 0.000 \\
\hline To or from toilet & 0.30 & 0.08 & 0.00 & 0.07 & 0.00 & 0.00 & 0.007 \\
\hline From floor & 0.00 & 0.10 & 0.08 & 0.00 & 0.00 & 0.30 & 0.014 \\
\hline Walking with patient & 0.00 & 0.00 & 0.69 & 0.00 & 0.00 & 0.00 & 0.000 \\
\hline To or from trolley & 0.05 & 0.08 & 0.08 & 0.14 & 0.00 & 0.30 & 0.192 \\
\hline Other transfer & 0.02 & 0.21 & 0.00 & 0.00 & 0.00 & 0.10 & 0.026 \\
\hline
\end{tabular}


transfers" were performed (eg, to or from X-ray tables, out of a car, etc). The nurses felt stressed and the patients, who in more than half of the cases weighed more than $80 \mathrm{~kg}$, lost control or, in one-third of the cases, resisted, obliging the nurse to make a sudden movement. Lack of information regarding transfer techniques contributed to one-third of the cases. The nurse transferred the patient alone in one-third of the cases. Lack of information concerning the patients' condition or demands on rehabilitation had no influence on this cluster.

Cluster 3: nurse walked alone with patient. The accident processes in cluster 3 (13 cases) often occurred when the nurses were walking alone with the patient, and they started when the patient lost control, obliging the nurses to make a sudden movement to prevent the patient from falling. In more than one-third of the cases, the patient had been prescribed rehabilitation. In addition a misunderstanding or lack of communication between the nurse and the patient contributed. Shortage of staff or the coworker had no influence on this cluster.

Cluster 4: unaided transfer of a patient in bed or to or from bed. In cluster 4 (14 cases) all concluding phases occurred when the nurse alone transferred a patient in the bed or to or from the bed. In more than half of these cases the nurses had chosen to work in an awkward position, whereas in the rest they were compelled to work in an awkward position. In half of the cases the nurse felt stressed. Lack of information on transfer techniques contributed to one-third of the cases. Rehabilitation requirements, lack of information concerning the patient's condition, and co-workers had no influence on this cluster.

Cluster 5: co-worker lost grip on patient during transfer in bed. Cluster 5 was small, with only 4 cases. They all occurred when a patient was transferred in bed and when the co-worker lost hold of the patient during the transfer. In 2 of the cases the nurses had chosen to work in an awkward position or had had to make a sudden movement. In one case, the patient resisted, and, in one case, the nurse lacked information on transfer technique. None of the other factors had any influence on this cluster.

Cluster 6: nurse chose awkward position due to stress. All nurses in cluster 6 (10 cases) had chosen to work in an awkward position, most often in combination with stress. The most frequent patient transfers were from the floor, to or from the trolley, or to or from the bed. In one-third, a contributing factor was lack of a transfer device. To nearly the same degree, the patient lost control or resisted. In this cluster there was no influence from rehabilitation demands, lack of information on transfer techniques, the patient's condition, co-workers, misunderstandings, lack of communication, or risk in the physical environment. Neither was the nurse compelled to work in an awkward position.

The mean ages of the nurses in the 6 different clusters varied between 30 and 36 years. The 1 -way analysis of variance showed that the 6 clusters differed significantly except for lack of information on transfer technique, which contributed to the accident processes in all the clusters except the last (number 6), shortage of staff, which contributed in all the clusters except numbers 3 and 5 , and patient transfer to or from the trolley, which contributed to all the clusters except number 5 .

\section{Discussion}

The study covered all reported occupational overexertion back injuries due to accidents among nurses in the Stockholm County hospitals in Sweden during 12 months. As almost all the cases were interviewed, we were able to obtain detailed information on the accident process. Six well-defined clusters and their pattern of factors contributing to the accident processes were identified, and they provided new knowledge about the most common accident processes occurring among nursing personnel. Despite the time span between the accident and the interview, no interviewer noted that the injured person had difficulties in remembering the details of the accident process. In contrast, many interviewers made remarks about how well the person remembered the details. One explanation might be that the injured nurse had already filled out an injury report and thereby had reflected upon the circumstances concerning the accident.

Most of the accident processes involved a patient transfer, as expected from an earlier study (5). This finding is also consistent with the results of other studies (7, $18-23$ ).

It was surprising that, in most cases, the concluding phase of the accident process (loss of control) occurred during ordinary planned patient transfers in which the nurse had time to prepare herself and the patient. This finding is in contrast to what has been found in industry, where very few accidents occur during ordinary tasks (24). Transfer devices were seldom used. As the nurses most often said that they had performed the task as usual, transfer devices were evidently used seldom in daily work; this result has also been found elsewhere (25).

Lack of training in lifting techniques contributed in most of the clusters, showing the need for training. The traditional approach to the teaching of lifting and handling techniques has shown little, or no, long-term benefit for back injuries (7). Studies are needed that compare different transfer techniques so that the most gentle way of transferring a patient, both for the nurse and the patient, can be found and also so that the best means for teaching the technique can be determined. In addition, 
the teaching of patient transfer techniques should be combined with training in how to handle transfer devices.

Of the factors assessed as directly contributing to the accident process, those separating the clusters were the type of patient transfer performed and whether the nurse transferred the patient alone. Another factor was a sudden event forcing the nurse to make a sudden movement, as also reported in a Canadian study (26). Yet another separating factor was that the nurse worked in an awkward position, either from choice or due to stress or because a risk in the physical environment compelled her to do so. Depending on the type of accident process, the different factors were involved to various degrees.

The 2 largest clusters ( 1 and 2 ) mainly involved transfers to or from the bed or toilet and transfers in the bed. Risks in the physical environment, most often due to lack of space, contributed in clusters 1 and 2 (as also in clusters 3 and 4). This situation either compelled the nurse to work in an awkward position or made it impossible for her to use a transfer device, and it therefore explains why nurses often choose to perform their tasks in a risky manner even when the patients are heavy and not cooperative. Owen \& Garg (23) showed that the most stressful patient handling tasks for nurses are transfers between the bed and wheelchair and between the toilet and wheelchair. This finding is supported by the results of our study, in which one-third of the patient transfers were to or from a wheelchair. Patient transfer frequently took place in the bed, a finding which is in agreement with the results of Gagnon et al (27), indicating that the load on the torso during the pulling and turning of patients in bed is high and can explain the incidence of low-back problems among nurses (27).

In many cases, particularly in cluster 2 , but also in clusters 1, 3, 4 and 6, a contributing factor was the lack of a transfer device, indicating that transfer devices need to be available, as should sufficient space for their use. The study shows the need for good transfer devices that are easy to use. It is also important to train nurses in how to handle the transfer devices in their own ward in order to make the use of devices a natural part of the job. The explanation of why transfer devices are so seldom used in hospitals is complex. Studies have found nursing personnel to be reluctant to use transfer devices because they did not understand how to use them or they lacked experience in their use $(28,29)$. Nurses might also feel that their duty is to nurse patients and that this duty includes manual transfers, while they find it impersonal and less human to transfer patients in a hoist. For this reason they perhaps assume that patients prefer to be transferred manually. Sometimes the patients also express this same opinion. These are possible reasons accounting for the differences in patient transfers, compared with handling heavy goods in industry, where the use of transfer devices is more natural for workers.
It came to light during the interviews that there is a need for training in emergency situations, such as if a patient has fallen to the floor. There were cases where the interviewed nurse said she had enough knowledge herself on how to transfer a patient using a hoist, but her co-workers became stressed and immediately wanted to transfer the patient manually. There should also be training in how to let patients down gently onto the floor when they have lost their balance, instead of working against gravity and trying to stabilize them.

A lack of information in transfer techniques contributed to all the clusters except number 6 . It seems that the nurses often relied, or had to rely, on their own and their co-worker's muscular strength and their ability to transfer patients manually. In two-thirds of the accidents, 2 or more nurses assisted the patient; this finding is similar to the results of St Vincent et al (26). Our study thus indicated that 2 or more nurses sharing the burden did not effectively prevent back injuries. To prevent back injuries among nurses, it is important to train them in how to transfer a patient, to plan the patient transfer, and to use a hoist whenever the patient needs to be lifted.

State registered nurses reported, both relatively and absolutely, more injuries than registered general nurses or auxiliary nurses. One reason may be that the general registered nurses do a smaller share of the practical nursing, and consequently make fewer patient transfers. The Swedish health care organization is changing, and eventually registered general nurses will do more of the practical nursing, including more patient transfers, and will thereby be at greater risk for back injury than previously, since transfers of patients sometimes lead to back injuries $(5,19-23,30)$.

Of the 6 persons who declined to participate in the study, some stated that they did not want to have that much attention. One nurse had been dismissed and therefore saw no reason to participate. A possible source of error could be that the amount of information given in the free description could differ depending on the nurse's ability and willingness to provide detailed information, for example, if she blamed herself. Furthermore, the skill of the interviewers and their ability to make the nurses feel secure during the interview probably influenced the answers since the information may have been of a delicate nature. However, the predominant attitude was very open, and many of the nurses said they were happy that someone took their claims seriously.

Only nurses who had been at work for at least 1 week during the 3 months preceding the reported injury were included in the study. This criterion was used to guarantee that the nurse had some knowledge about the current work and the environment. Thus none of the reported injuries occurred during the first 6 days at work. Statistics from $1985-1986$ show that $2 \%$ of accidents leading to more than 1 day of sick leave among Swedish nurse's 
aides occurred among persons with less than 1 week's experience on the job. Some injuries are probably never reported, the result being an underestimation, as shown in earlier studies $(18,31-33)$. In our study, probably very few of those who filled out an injury form were missed, as the study was performed in direct cooperation with the occupational health care organization, which receives a copy of every injury report.

The cluster analyses were based on the assumption that the factors directly contributed to the accident process and not simply to the current accident. The clusters thereby provide a good foundation for choosing effective preventive measures. The differences in the clusters showed the complexity of these kinds of accident processes; it also showed that measures for prevention, or the blocking of an accident process once started, have to be of different kinds and also present at several different levels in the organization. Some examples are the environment, transfer devices, knowledge, instructions, safety promoting norms, and safety policies. In many cases the most effective measure would be to improve the physical conditions (eg, shortcomings in the physical environment or the lack of transfer devices) that compel the nurse to work in an unsafe way. For a large group, however, organizational factors contributed to the accident processes; this result shows the need for better staff planning, for providing information to and training of nurses, for better planning of rehabilitation, and the like. The nurses sometimes felt they had to perform the task in an awkward position due to stress. The clusters showed a complexity in the accident processes and indicated that preventive measures should be targeted simultaneously at the organization of the work, the workplace, and the nurses' skill. Work design should incorporate several barriers for accident processes (34).

\section{Concluding remarks}

Reported back injuries due to overexertion occurred the most often during patient transfer, when a risk was present in the physical environment and when shortcomings in the organization were present, for example, under the following conditions: (i) transfer in the bed or to or from the bed and to or from the toilet, (ii) when no transfer devices were used, or (iii) when the patients suddenly lost their balance or resisted during the transfer, causing the nurses to make sudden movements.

\section{Acknowledgments}

We wish to thank Professor Anders Kjellberg for introducing us to the cluster analysis method and for his great support in discussions of the analysis.
Financial support from the Swedish Work Environment Fund and the Stockholm County Council is gratefully acknowledged.

\section{References}

1. Dehlin O, Hedenrud B, Horal J. Back symptoms in nursing aides in a geriatric hospital. Scand J Rehabil Med 1976;8:4753.

2. Harber P, Billet E, Gutowski M, SooHoo K, Lew M, Adele R. Occupational low-back pain in hospital nurses. J Occup Med $1985 ; 27: 518-24$.

3. Ljungberg A-S, Kilbom $\AA$, Hägg GM. Occupational lifting by nursing aides and warehouse workers. Ergonomics $1989 ; 32: 59-78$.

4. Venning PJ. Personal and job-related factors as determinants of incidence of back injuries among nursing personnel. J Occup Med 1987;29:820-5.

5. Engkvist I-L, Hagberg M, Lindén A, Malker B, Over-exertion back accidents among nurses' aides in Sweden. Safety Sci 1992;15:97-108.

6. Troup JDG. A model for the investigation of back injuries and manual handling problems at work. J Occup Accid 1988;10:107-19.

7. Hignett $S$. Work-related back pain in nurses. J Adv Nurs $1996 ; 23: 1238-46$.

8. Laflamme L. A better understanding of occupational accident genesis to improve safety in the workplace. J Occup Accid 1990;12:155-65.

9. Andersson R. The role of accidentiology in occupational injury research. Solna (Sweden): National Institute for Working Life, 1991. Arbete och Hälsa, no 17.

10. Andersson R. Between different worlds. In: Menckel E, Kullinger B, editors. Fifteen years of occupational accident research in Sweden. Stockholm: Swedish Council for Working Life Research, 1996:17-25.

11. Hagberg M, Christiani D, Courtney TK, Halperin W, Leamon TB, Smith TJ. Conceptual and definitial issues in occupational injury epidemiology. Am J Ind Med 1997;32:106-15.

12. Kjellén U. Analysis and development of corporate practices for accident control [dissertation]. Stockholm: The Royal Institute of Technology, 1983.

13. Kjellén $U$. Improving the efficiency of safety management in industry. In: Menckel E, Kullinger B, editors. Fifteen years of occupational accident research in Sweden. Stockholm: Swedish Council for Working Life Research, 1996:26-36.

14. Engkvist I-L, Hagberg M, Wigaeus Hjelm E, Menckel E, Ekenvall L, PROSA Study Group. Interview protocols and ergonomic checklist for analysing overexertion back accidents among nursing personnel. Appl Ergon 1995;26:21320.

15. Clayton D, Hills M. Statistical models in epidemiology. Oxford: Oxford University Press, 1993:11-7.

16. Everitt B. Cluster analysis. 2nd ed. Bungay, Suffolk (Great Britain): The Chaucer Press, 1980:1-22.

17. Norusis MJ. SPSS base system user's guide. Chicago (IL): SPSS Inc, 1990:520-66.

18. Owen BD. The need for application of ergonomic principles in nursing. In: Asfour SS, editor. Trends in ergonomics/human factors IV. North Holland: Elsevier Science Publishers BV, 1987:831-8. 
19. Cato C. Incidents, prevalence and variables associated with low back pain in staff nurses. Am Assoc Occup Health Nurses J 1989;40:321-7.

20. Estryn-Behar M, Kaminski M, Peigne E, Maillard MF, Pelletier A, Delaporte MF, et al. Strenuous working conditions and musculoskeletal disorders among female hospital workers. Int Arch Occup Environ Health 1990;62:47-57.

21. Jensen RC. Back injuries among nursing personnel related to exposure. Appl Occup Environ Hyg 1990;5:38-45.

22. Stobbe TJ, Plummer RW, Jensen RC, Attfield MD. Incidence of low back injuries among nursing personnel as a function of patient lifting frequency. J Saf Res 1988;19:21—8.

23. Owen BD, Garg A. Reducing risk for back pain in nursing personnel. Am Assoc Occup Health Nurses J 1991;39:2433.

24. Saari J, Lahtela J. Work conditions and accidents in three industries. Scand J Work Environ Health 1981;7 suppl 4:97105.

25. Garg A, Owen B, Carlsson B. An ergonomic evaluation of nursing assistant's job in a nursing home. Ergonomics 1992;35:979-95.

26. St Vincent $M$, Tellier C, Petitjean-Roget T. Analysis of transfer accidents in three hospitals. In: Bittner AC, Chapney PC, editors. Advances in industrial ergonomics and safety VII. London: Taylor \& Francis, 1995:931—5.
27. Gagnon M, Akre F, Chehade A, Kemp F, Lortie M. Mechanical work and energy transfers while turning patients in bed. Ergonomics 1987;30:1515-30.

28. Bell F. Patient lifting devices in hospitals. London: Groom Helm, 1984.

29. Owen B. Patient handling devices: an ergonomic approach to lifting patients. In: Aghazadeh F, editors. Trends in ergonomic/human factors V. North-Holland: Elsevier Science Publishers BV, 1988:721-8

30. Owen BD. Personal characteristics important to back injury. Rehabil Nurs 1986;11:12-6.

31. Stubbs DA, Buckle PW, Hudson MP, Rivers PM, Worringham CJ. Back pain in the nursing profession, 1: epidemiology and pilot methodology. Ergonomics 1983;26:755-65.

32. Owen BD. The magnitude of low-back problems in nursing. West J Nurs Res 1989;11:234—42.

33. Collins $\mathrm{M}$. A comprehensive approach to preventing occupational back pain among nurses. J Occup Health Safety $1990 ; 6: 361-8$.

34. Backström T, Accident risk and safety protection in automated production. Stockholm (Sweden): National Institute for Working Life, 1996. Arbete och Hälsa no 7.

Received for publication: 31 October 1997 